\title{
Corrigendum: Transplantation of Normal Adipose Tissue Improves Blood Flow and Reduces Inflammation in High Fat Fed Mice With Hindlimb Ischemia
}

\author{
Liyuan Chen ${ }^{1,2}$, Lin Wang ${ }^{1,2}$, Yongjie Li ${ }^{1,2}$, Liqun Wuang ${ }^{1,2}$, Yaofang Liu ${ }^{3}$, Ningbo Pang ${ }^{1,2}$, \\ Yulin Luo ${ }^{1,2}$, Jing $\mathrm{He}^{1,2}$, Liping Zhang ${ }^{1,2}$, Ni Chen ${ }^{1,2}$, Rong $\mathrm{Li}^{1,2 *}$ and Jianbo $\mathrm{Wu}^{1,2,4 *}$ \\ ${ }^{1}$ Drug Discovery Research Center, Southwest Medical University, Luzhou, China, ${ }^{2}$ Laboratory for Cardiovascular \\ Pharmacology of Department of Pharmacology, The School of Pharmacy, Southwest Medical University, Luzhou, China, \\ ${ }^{3}$ Department of Gynaecology and Obstetrics, The Affiliated Hospital of Southwest Medical University, Luzhou, China, ${ }^{4}$ Dalton \\ Cardiovascular Research Center, University of Missouri, Columbia, MO, United States
}

OPEN ACCESS

Edited and reviewed by:

Miles J. De Blasio,

Baker Heart and Diabetes Institute,

Australia

${ }^{*}$ Correspondence:

Rong Li

hubeilirong@126.com

Jianbo Wu

wuji@missouri.edu

Specialty section: This article was submitted to Integrative Physiology, a section of the journal

Frontiers in Physiology

Received: 09 May 2018 Accepted: 24 May 2018 Published: 05 June 2018

Citation:

Chen L, Wang L, Li Y, Wuang L, Liu Y, Pang N, Luo $Y, H e J$, Zhang $L$,

Chen N, Li R and Wu J (2018) Corrigendum: Transplantation of Normal Adipose Tissue Improves Blood Flow and Reduces Inflammation

in High Fat Fed Mice With Hindlimb Ischemia. Front. Physiol. 9:717. doi: 10.3389/fphys.2018.00717
Keywords: arteriogenesis, inflammation, adipose tissue, blood perfusion, high-fat diet

\section{A corrigendum on}

Transplantation of Normal Adipose Tissue Improves Blood Flow and Reduces Inflammation in High Fat Fed Mice With Hindlimb Ischemia

by Chen, L., Wang, L., Li, R., Wang, L., Liu, Y., Pang, N., et al. (2018). Front. Physiol. 9:197. doi: 10. 3389/fphys.2018.00197

During resubmission of the version of the manuscript, a previous version of Figure $3 \mathrm{~A}$ was required by reviewer to merge images. We accidentally uploaded wrong images (Figure 3A, sham group; F8/40 staining) in the final version. The correct version of Figure 3A appears below. The authors sincerely apologize for the error. This error does not change the scientific conclusions of the research article.

The original article has been updated.

Conflict of Interest Statement: The authors declare that the research was conducted in the absence of any commercial or financial relationships that could be construed as a potential conflict of interest.

Copyright (c) 2018 Chen, Wang, Li, Wuang, Liu, Pang, Luo, He, Zhang, Chen, Li and Wu. This is an open-access article distributed under the terms of the Creative Commons Attribution License (CC BY). The use, distribution or reproduction in other forums is permitted, provided the original author(s) and the copyright owner are credited and that the original publication in this journal is cited, in accordance with accepted academic practice. No use, distribution or reproduction is permitted which does not comply with these terms. 


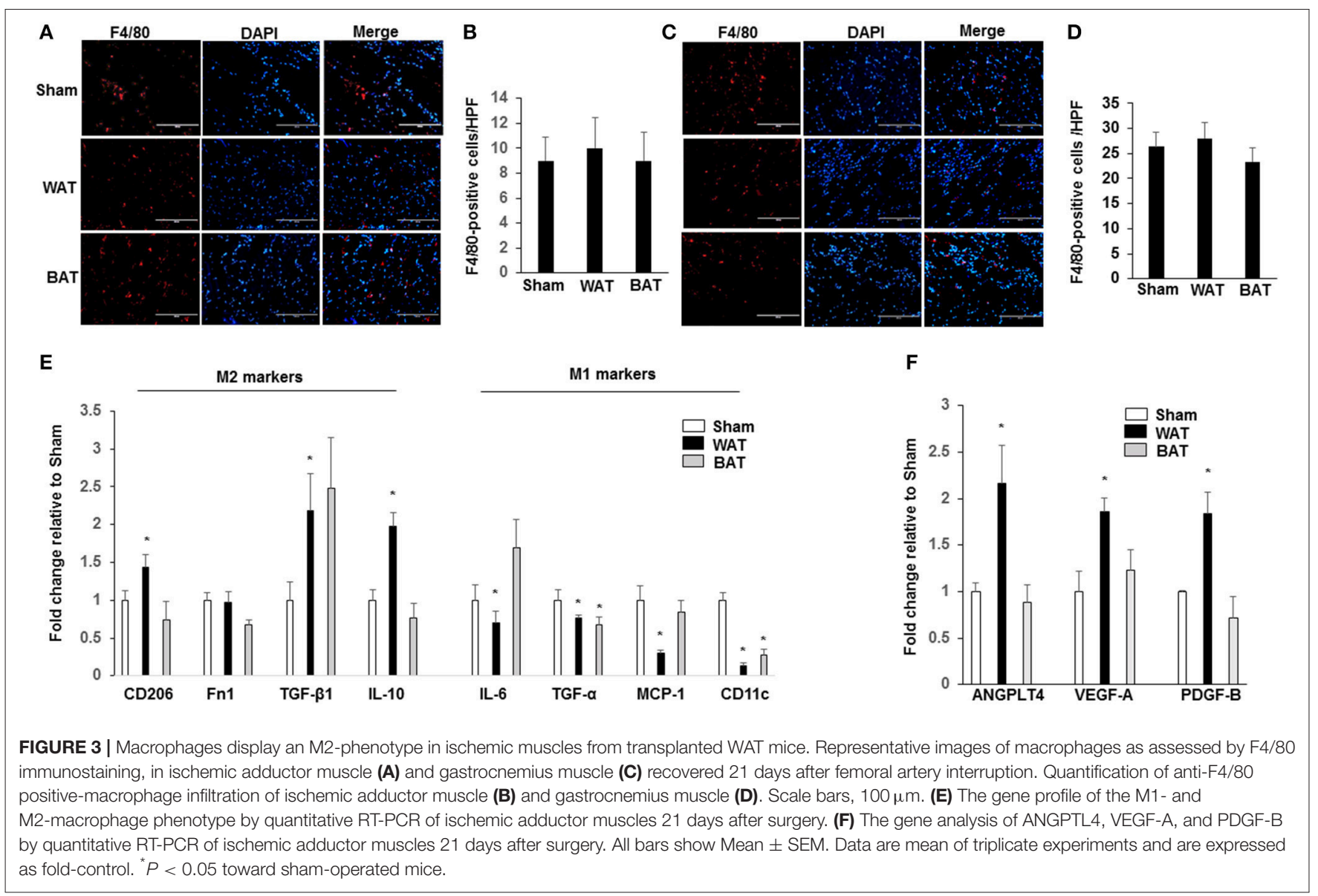

